\title{
Urban/Spatial Planners and Power: The Role of Time and Scale ${ }^{1}$
}

\author{
Lucia Dobrucká
}

\begin{abstract}
This study combines existing approaches to power according to how they reflect the factors of time and scale, and shows how these lenses might inspire planners to rethink their roles in a more holistic manner. Planners' perception of power differs significantly depending whether they understand change in terms of continuous evolution or discontinuous eras. A desire to understand the complex processes in which cities evolve puts planners in a rather passive role as trend-watchers, analysts and moderators. In the second case, planners' perceptions and roles vary according to how continual evolution is disconnected and how the factors of space and time are applied. First, if "context" is understood as the fundamental base, planners see their roles mainly as describing the situation at hand and opposing those with power in terms of providing relevant information, setting up appropriate agendas and keeping to specific terms. Second, planners who highlight "context-free values" (or good intentions) prefer to see their role as keeping their eyes on fair processes, maintaining a balance among participants, striving for mutual trust and being advocates of those without power. Third, if planners focused on "participants' behaviour", which is often rooted in individuals' subliminal perceptions, they might also tend to nudge participants in the desired direction and frame tasks, anchor discussions and inhibit automatic reactions in favour of careful considerations.
\end{abstract}

KEY WORDS Urban/spatial planning, planners, power, time, scale, complexity, subliminal perceptions

\section{Introduction}

This article offers a critical review of the state of art in the subject of how "power which causes social dynamics" has been considered in the discourse of urban and spatial planning, and how the traditions of thoughts regarding power have been reflected by urban/spatial planners, particularly at the level of cities. While urban planning deals with the physical development of cities, spatial planning enlarges this field by connecting urban planning to its strategic and socio-economical aspects. Hence, the term "planner" in this article means urban/spatial planners as well as experts, scholars and the authors of development documents who are connected with planning processes and possess power to influence city development generally, such as municipal employees, architects, researchers in the field, and others. This paper presents a review of the problem in planning studies, and it structures diverse approaches to power according to how different authors have coped with the factors of time

Sociálni studia / Social Studies 4/2016. Pp. 45-60. ISSN 1214-813X.

1 Acknowledgement: This article was supported by the International Visegrad Fund. 
and scale. This unusual system reveals that there are some features of power which are yet not fully recognised by planners - for instance a power of subliminal fringe - and advises planners to reconsider their roles.

The analysis presented here draws on Weber's perspective of historical evolution; nevertheless, it also looks for a new way to frame and systematise diverse approaches in which power has been understood, studied and evaluated. Three points are taken into account. First, approaches to power differ significantly depending on whether we favour continuous evolution or discontinuous eras and, in the second case, how continual evolution is disconnected. One specific mechanism - a tripled spiral - is uncovered at this level. Second, concrete observations of what is happening, and who is acting, when and how, involve the factors of scale (e.g. society, city and person) and time (e.g. the time-spatial characteristics of particular phenomena, affairs and events). These two factors are relative; power in a long-term perspective is often in opposition to power as it works during particular moments. Such relativity allows for a wide range of interpretations while remaining well structured. And third, special attention is paid to the scale of individuals. The discourse in planning focuses mainly on how power is distributed among actors, how actors interact and use their specific types of power. But (neo)liberal democracy is by definition individualistic, and neglecting the role of individuals in such an individual-driven society is major cause of many problems planners face.

\section{Power of c ontinuous evolution}

Batty (2010: 115-117) argued that "interventions are potentially destructive unless we have a deep understanding of their causal effects" and "slight changes in direction are thus preferred to radical top-down restructuring whose implications might be far reaching and completely unpredictable". Today, many urban/spatial planners treat cities as complex systems which evolve by their own rules and believe that planners, who cannot fully understand and manage such systems, should not interfere (e.g. de Roo and Silva 2010; Hillier, de Roo and van Wezemael 2012). Planners focusing on complex systems generally prefer making careful observations to taking proactive actions and hesitate to lead city development; they proclaim that local participants are the ones who should make decisions. The planner's role is perceived mainly as a mediator, trend watcher and transition manager (de Roo 2010: 35), and this rather passive position has attracted increasing attention in modern planning discourse. However, "a power of system", which is out of human control, is not a product of contemporary complexity theories; it is traceable in the texts of past thinkers, too. And it seems to be based on one specific pattern - a triple spiral.

Among the early thinkers, the work of Max Weber is crucial for this paper. His texts concerning the development of medieval European cities and cities in ancient Greece (Weber 1997) allow us to sense a spiral of three interconnected elements: intentions (in terms of society's self-perception, ideas and desires), participants' behaviour (what people in society do or do not do) and context (meaning conditions which are formed by society's behaviour and which form society's intentions). These three continuously evolving elements, from the Weberian perspective, can be briefly described like this: 
Historical circumstances designate what people in a particular society think. People's selfperception (society's self-image) determines what people (society) do. The results of their actions are directly incorporated into the development, modification and change of the social context. Social context means the particular situation in which society occurs and which serves as a base for new ideas. And so on.

A similar observation can be derived from Foucault's texts about discipline (Foucault 1979, 1998) and biopolitics (Foucault 2007). Both concepts describe how slow evolution in society shapes the minds of individuals and groups, and influences their behaviour, as well as how individuals' and groups' behaviour modify society. Planners who dwell on Foucauldian discourse analysis pay attention to how meanings evolve and form hegemonies (such as Assche, Duineveld, Beunen and Teampau 2011; Assche, Beunen and Duineveld 2012). Gunder and Hillier (2009), Gunder (2010), Sager (2015) and others address planning as an ideology in the sense that it produces narratives about a desirable future. Grange (2014) illustrated how the use of language shaped beliefs and beliefs shaped acts that formed planning culture in Denmark. Jones (2011) studied how the claims of elite architects created the social meaning of prestigious buildings, and how, subsequently, social imagination shaped the entire field of architecture and other architects' behaviour. Gunder (2011) offered an insight into the power of professional discourse which forms the "correct" beliefs, attitudes and working outcomes of young planners. On closer inspection, the power of specific meanings evolves and turns to ideologies along the same triple spiral as in Weber's analysis - a spiral of intentions (meanings), participants'behaviour (what people do to fulfil the meanings they believe in) and context (situations which are formed by participants having beliefs and which predefine new meanings).

The recent concept of power which describes the mechanisms that shape society from a long-run holistic perspective is Lukes's third dimension of power. The first dimension refers to the most basic domination of A over B, mostly by using force, coercion and sanction. The second dimension involves non-behaviour, in the sense that $\mathrm{B}$ fails to act because it expects A's action (a threat of force, coercion and sanction). The third dimension compliance to domination - works as a part of a social context, such as the education system, legislative framework and cultural values. It possesses discreet, undistinguished or even obscure forms, e.g. learning, practical training, experience, communication, propaganda, conventions, social pressure, and many others. Hence, this kind of power affects the human mind as it "prevents people from doing, and sometimes even thinking" (Lukes 2005: 50). Lukes questioned how this kind of power slowly shapes participants' motives, values and beliefs. And vice-versa, how participants, who follow the common social context consciously, or rather automatically, help to co-evolve the social context with their everyday ideas, (non) decisions and (non)behaviour. In Lukes's perspective, things evolve as part of a complex system which evolves in the same spiral as the one above: interactions take place between the element of context (society), the element of intentions (beliefs, ideas and values shaping human minds) and the element of participants' behaviour (in terms of human behaviour as well as non-behaviour).

I argued above that planners who focus on self-evolving systems tend to be more reactive than proactive. The reasons for this can be found in psychology. Kahneman (2011) 
stated that humans prefer non-activity to activity. This is caused by their mental expectations that regret that comes from a loss which was actively caused is many times higher than regret caused by being passive ("I deserved it" versus "I had bad luck"). Also, the guilt which society attributes to an involved person is much higher in cases where he/she participated actively. Therefore, in a situation when decisions might cause negative outcomes, unpleasant feelings and responsibility, most people choose to do nothing. This might be a reason why, when sensing the power of evolution, planners who perceive cities as complex systems hesitate to interfere. In continuous evolution, three elements are reiterated over time, and none of these elements is dominant enough to be marked as the one that hides power. Power seems to lie in the triple spiral per se, the evolution of history, and, if this is true, it could hardly be captured by humans. This is what we generally sense when pointing to determination - we compare individuals to uncontrollable history. Lukes's compliance to domination, Foucault's discipline, Gunder's education of young planners, and other theories suggest that the scale of society (society as one entity) is superior to the scale of individuals (one single man); the situation in which a person lives (such as one's country, historical circumstances and education system) considerably shapes his/her own life. Based on Kahneman's conclusions, non-activity seems much safer than activity in this broad longterm perspective.

One might argue that planning does not simply reflect social forces; it also uses positive authority to create things, redefines politics and produces the new sources of legitimacy (e.g. Sandercock 2005; Jones 2011; Getimis 2012; and others quoted below). I completely agree. Even the research by planners who pay attention to complexity often focuses on questions like: to what extent should planners influence complex systems and what are the key factors enabling them to do so? My point is that this proactive power of planners can hardly be observed at the scale of continuous evolution and under the rules of complex systems - we need to change the scale, disconnect evolution, zoom into particular events and "simplify" the task. And how we do this matters.

\section{How we disconnect evolution detemines how we perceive power}

The perspective of evolution introduced above has a weakness: even though it involves the element of participants' behaviour, this element is based on a view of society as a whole rather than that of particular individuals/groups with their goals, decisions and tactics. If we wish to penetrate deeper into "something concrete", we need to disconnect the evolution and extract the object of our study. Since the triple spiral contains three elements, there are three options for commencing observations, considerations and interventions: via the elements of context (e.g. Sun Tzu, Machiavelli and Foucault), intentions (e.g. Plato, Kant and Habermas) or participants' behaviour (e.g. Aristotle, Bourdieu and Arendt). As the famous names in parentheses and their fundamental distinctions indicate, the element in which the spiral is disconnected is significant in terms of how power is treated.

Probably the most widely used approach today is to start with the element of context. We generally agree that plans, decisions and actions should be based on the situation at hand, because historical, social and cultural contexts predefine what society accepts as good and 
rejects as bad (e.g. MacIntyre 1988; Campbell and Marshall 1999; Watson 2006). Planners' belief in the crucial influence of context has resulted in a great number of case studies that underpin the modern discourse in planning. Most journals call for local, empirical and comparative studies. The analyses of power, as well as of resistance against power, are largely rooted in specific examples which connect real-life affairs to participants and their tactics (e.g. Flyvbjerg 1998, 2002; Richardson 2005; Fox-Rogers and Murphy 2014). Planners who highlight specific contexts see their roles mainly as observing, analysing and describing the situation at hand, or opposing power structures by providing information relevant for a particular case, setting up appropriate agendas and keeping to specific terms (e.g. Forester 1982, 1989; Flyvbjerg 2001). Also, planners who deal with uncertainty generally turn to the unpredictable changes of context. They warn about turbulent changes (in terms of unpredictable accidents, coincidence or luck) and stress the importance of abilities such as flexibility, adaptability and multitasking (e.g. Christensen 1985).

Yet, other thinkers break the triple spiral of evolution through the element of intentions, as they believe that intentions to achieve universal values should guide human behaviour regardless of context. In planning studies, this approach builds on Habermas (1984, 1990, 1992). It seems that the Habermasian approach starts with correct process (communication), but, in fact, process is preceded by intentions to maintain morality, create an ideal speech situation and reach consensus. Habermas considered the concept of discourse ethics universal, and his approach neglected the power of context (communicative rationality is context-free), individual participants (all are supposed to behave as equals) and individual goals (original aims are modified under the process of communication). Hence, for Habermas, power should be hidden exclusively in means like standard procedures, methods and tools. Consequently, planners who dwell on the Habermasian approach trust the power of means and consider their roles mainly as guarding processes, facilitating discussions and maintaining a balance among participants (e.g. Healey 1997; Forester 2000). But besides means, the element of intentions also points to the power of intentions per se. Some concepts, such as democracy, ethics, justice, tolerance, truth, participation, and others, seem to be treated universal regardless specific context. Planners who have these universal intentions in mind are used to arguing that they should keep their eyes on fair processes, strive for mutual trust and be advocates for those without power (e.g. Campbell and Marshall 1998; Stein and Harper 2003; Pløger 2004; Hoekveld and Needham 2013). Contrary to those who favour context and call for flexibility, adaptability and multitasking, planners who prefer intentions stress that, in the planning profession, consistency, steadiness and striving for ethics is more desirable than the ability to change minds along with the change of context.

In the last case - if evolution is disconnected via the element of participants' behaviour - events are simply happening rather than being intentionally planned or inspired by the situation at hand. Rather than to the unpredictable change of context, this third element points to spontaneous human actions, which are often emotional, intuitive and sudden. This perspective is partly reflected in Aristotle's concept of phronesis. Practical wisdom, which is widely considered to be an automatised professional reaction, was applied to planning via the role of planners as experts and is regaining attention today (e.g. Bourdieu 1977; Flyvbjerg 1998, 2001; Gunder 2003). Nevertheless, spontaneous human actions beyond expertise are 
yet not systematically examined in planning discourse. Contributions exploring the emotional part of planning, as well as studies about the influence of subliminal factors on planning and their inhibitory control, are still rare (e.g. Hoch 2006; Baum 2011; Houdé and Borst 2014). Therefore, to observe the power of the subliminal, we need to consult scientific disciplines such as political science, cognitive science and psychology. For instance, Arendt (1958) stressed that spontaneous actions dominate the political domain. Since planning is political in terms of the exercise of practical power to influence things, spontaneous actions could be the most frequent factors in planning. Kahneman (2011) demonstrated that most human actions come out of the sub-consciousness rather than the consciously considered external situation. His conclusion that humans do not behave rationally is applicable to stakeholders as well as planners themselves. Thaler and Sunstein (2009) questioned humans' abilities to make decisions when facing complex, unique, long-term and unforeseeable situations. Their conclusions are extremely interesting for planners, who perform in these kinds of situations. The element of participants' behaviour could help planners to rethink their roles from the perspective of emotions, irrationality and biases. I will come back to this topic in the last section of the paper.

\section{Power and the factors of time and scale}

As I already noted, if we wish to penetrate deeper into "something concrete", to understand what is happening and how, who performs, under what circumstances and why, we need to disconnect the spiral of evolution and specify the object of our study. This section will illustrate how authors' perceptions of power vary according to the different elements through which the spiral is disconnected (as described above) and the factors of time and scale that are used for explorations. Time and scale make a huge difference; power working in the longterm perspective often operates in opposition to power as it works during particular moments. The distinction between "long-term" and "moment" is relative and depends on scale. "Years" can mean a long-term perspective on the scale of individuals but a moment for society, and "hours" may cause the key modification of a particular development project while being invisible when analysing historical affairs. Authors compared here are Habermas, Foucault, Healey, Flyvbjerg, Forester, Arendt and Machiavelli.

Contemporary planning is largely framed by the works of Habermas and Foucault. In my opinion, the reason these thinkers are usually considered incompatible is that they work on different scales, use different time-perspectives and each prefer a different starting element for their observations. Habermas $(1984,1990,1992)$ disconnected the flow of evolution via the element of intentions (to follow discourse ethics) and rooted his approach in an ideal speech situation, which, as a matter of fact, remains a meeting. From the perspective of scale and time, Habermas advised how a specific group of participants should act in a given place during a short period of time. Hence, even though communication is perceived to be universal and guided by the supreme discourse ethics, Habermasian rationality is primarily a tool that works during specific short-term events. This may be one reason why communicative planning faces heavy criticism when it is used as a panacea (e.g. de Roo and Silva 2010; Gunder 2010; Purcell 2009). On the contrary, Foucault (1979, 1998, 2007) disconnected 
the flow of evolution via the element of context, and analysed how particular phenomena evolved inside large time-spatial ranges, e.g. how mad men were treated during various centuries, how sexuality worked in the Roman Empire, and how neoliberalism influenced the German economy. When analysing phenomena under relatively stable but long-lasting time-spatial characteristics, Foucault identified the pools of actors and the power relations inside those pools. Since reciprocal influence becomes visible after a long time, Foucault, not Habermas, could proclaim that power is dynamic, symmetric and based on relations inside the pool.

A similar variation is observable in two other texts that significantly influenced planning theory. Flyvbjerg's Rationality and Power (1998) analysed the power structures among stakeholders in Aalborg over 15 years whereas Healey's A Planner's Day (1992) described one planner's performance in Manchester during one day. On the one hand, we have a context-based approach, a relatively large scale (city) and a relatively long period of time (15 years). Thus, Flyvbjerg could study diverse participants, who were changing their tactics according to how the project proceeded, how relationships evolved and how unexpected coincidences intervened. He was able to identify the dominant power structure, a large range of applied strategies and the outcomes of alternative decisions. On the other hand, there is the small scale (individual planner), a short period of time (one day) and a leading intention to follow communicative planning practice. Contrary to the case of Aalborg, where each stakeholder, event and method was only one of many, the time-spatial characteristics chosen by Healey resulted in no consequences which would last for more than a few hours being identified. Therefore, Healey could have seen a planner as a key participant, bound power to the correct processes, and proclaimed communication to be a universally desirable method. This does not reduce the value of Healey's article. It simply means that the element we choose to disconnect evolution together with time-spatial characteristics for observations predefines our perspective, the factors we see as crucial, where we look for power, and which planners' roles we consider to be adequate.

Forester $(1982,1989)$, one of the most quoted authors regarding the challenge of power in planning, argued for a pragmatic approach to what planners can do in the face of power: to influence the conditions of the planning process. To formulate the task at hand, set up the agenda, choose participants, organise data, anticipate misinformation, prepare proactive arguments - by definition, Forester's claims focus on a particular context of meetings, projects and plans. Even though this seems to be a generally applicable advice, its practical feasibility is rooted in specific events. Authors promoting so-called practical ethics, e.g. Forester (1989, 1999), Pløger (2004), Richardson (2005) and others, paid attention to ethical judgements which were made under a power structure that encouraged or threatened specific conduct. Planners' power, as seen via this tradition of thinking, is based on the context at hand, a relatively short time and small scale. Hence, when applying practical ethics, planners need to testify to their reliability, grasp the fleeting opportunity and bear disappointment when the next project makes them start all over again. In contrast, normative ethics calls for good intentions which extend beyond any given context, run across scales and last for a longer time. For instance, Stein and Harper (2003) discussed the importance of trust in planning as an alternative to Foucauldian power discourse. Even though "trust" implies various meanings, it 
is a normative category. Trust requires a relatively long-lasting experience which is oriented towards good intentions and goes beyond one specific event. Hoekveld and Needham (2013) suggested an ethical code to be developed for planning agencies. Again, such a normatively oriented endeavour would surpass individual case studies and strive for a relatively long-time oriented set of rules applicable across diverse scales.

Indeed, the distinction between relatively short-term and long-term lenses is crucial if we wish to understand how power works in the cases of particular phenomena, events or people. Time-based optics, and their connection to the three elements described above, are strongly underlined in the work of one particular theorist of power, Niccolò Machiavelli. He stated that gaining power, which is often a short-term business, demands different circumstances and personal qualities than keeping power in the long term. A ruler "should take from Severus those qualities that are necessary to found his state, and from Marcus those that are suitable and glorious in order to conserve a state that is already established and stable" (Machiavelli 1998). When Machiavelli analysed the cases of Moses, Cyrus, Romulus and Theseus, whom he considered the most extraordinary men, he wrote:

In examining their deeds and their lives, one can see that they received nothing from Fortune except opportunity, which gave them the material they could mould into whatever form they liked. Without that opportunity the strength of their spirit would have been exhausted, and without the strength, their opportunity would have come in vain. (Machiavelli 1998)

To gain power, one needs to balance opportunity (the element of context) with his/her abilities to use such opportunity (the element of participants' behaviour). The element of intentions in terms of rational motives, inspiring visions and strategies is useful, but not necessary; power can be gained by a single act. On the contrary, to keep power for a long time, good motives, innovative ideas and practical plans (which can be ascribed to the element of intentions) are more important than unstable luck. Gaining power can be a single act rooted in harmony between context and behaviour, whereas keeping power in the long-term encounters all three elements of the evolution spiral. Today, the distinction between gaining power and keeping it, which is primarily a matter of time, might be useful to understand democratic politics. Political behaviour is based on a relatively short-term cycle of elections instead of long-term achievements. Therefore, it follows the mechanisms of how to gain power rather than how to keep it. This means that politicians who behave under a regime of four-year-long political cycles may use good motives, inspiring ideas and rational thinking; but they are not obliged to do so.

The last element by which the evolution spiral can be disconnected is participants' behaviour. Through the lenses of time and scale, one's behaviour is observable as here-andnow acts; especially when talking about spontaneous human actions. Emotions, intuitions and sudden decisions are probably the shortest moments (a kind of enlightenment), which appear at the smallest scale (an individual's mind). In planning, this is a huge problem - the contrast between the time-spatial characteristics of territories, which evolve slowly as complex systems, and the time-spatial characteristics of spontaneous human actions, which are fragmented, deciduous and ungraspable. As an example, I will name one author who dared to combine these incompatible perspectives, Hannah Arendt. The Origins of Totalitarianism 
(Arendt 1979) focused on civil servants' behaviour during Nazi Germany. She observed how obedience, thoughtlessness and routinised behaviour allowed for the spontaneous establishment of the entire republic, and how the Second World War just "happened". According to Arendt's results, the narrow time-spatial features of the element of participants' behaviour accelerate the very specific mechanisms of power (such as unceasing change, extreme adaptability and a missing sense of continuity), make the standard tools of power control non-functional (e.g. laws produce obedience, standard procedures reduce critical judgement, and the large number of participants results in mass psychology) and leave powerful groups with literally no limits. Planning discourse admits that human actions are influential; however, the contrast between the scale of individuals' spontaneity on one side and the scale of large evolving systems on the other is not sufficiently addressed.

Even though planners are generally aware of the factors of time and scale, these factors are often underestimated. In my opinion, one example is the use of complexity theories in planning (e.g. de Roo and Silva 2010; Hillier, de Roo and van Wezemael 2012). As I discussed earlier, complexity is a feature of entities which evolve continuously during history (on a relatively large scale over a long period of time). Nevertheless, planners promoting complexity aim to ponder the very opposite issues - a wide range of factors during relatively short-term, space-limited and unstable projects. This contradiction raises misleading expectations. For instance, speaking of power, as planners observe a wide range of interactions among various participants, they expect these participants to influence each other similarly as they do in Foucault's pool of actors. But even though the large number of stakeholders helps to control individual participants' power, it does not support the symmetry of power in terms of power sharing, equality and mutual influence; this kind of Foucauldian symmetry is an outcome of time, not of a number. The task of describing "everything" under limited time-spatial conditions is challenging, and so far unresolved. Using complexity theories in planning is a relatively new direction and there are neither key thinkers representing it, nor agreed methods of doing it. The risk here is that planners who feel helpless when considering the power of systems might "give up in advance", even during relatively short-term projects in which active intervention would be desirable.

\section{Power of individuals and their subliminal perceptions}

Among various times and scales, specific attention should be paid to individuals who do not simply follow the evolution, but who adopt a proactive approach and use their power to make a difference. My perspective here remains Lukes's term "exercise of power" meaning that "rather than as a case of structural determination [...] it is in the exerciser's or exercisers' power to act differently" (Lukes 2005: 57; italics in original), or, in other words, "power refers to an ability or capacity of agent or agents, which they may or may not exercise" (Ibid.: 63).

In planning, opinions about the role of planners change as individuals change. In the past, technical rationality promoted planners as experts having the power to lead plans, decisions and actions. Later, the participative approach attributed power to local participants rather than planners and put planners in the role of moderators, facilitators and 
the guardians of correct process. The currently influential understanding of cities as selfevolving complex systems favours rather passive observations, analyses and considerations. Researchers exploring power often advise a proactive attitude; nevertheless, such statements remain careful not to contradict the general opinion regarding the power of stakeholders. Proactivity does not imply a planner's own interference in substantive matters but, rather, his/her support for other actors. For instance, Forester (1982: 67) suggests that planners use information, agenda-setting and moderation to "improve the quality of their analyses and empower citizen and community action". Campbell and Marshall (1998), Pløger (2004) and Richardson (2005) stressed the importance of ethical planning, which commonly refers to opposing those with power, and instead empowering citizens. Schmidt-Thomé and Mäntysalo (2014) suggested learning as a key to overcoming powerful groups. Probably the most radical alternative was suggested by Flyvbjerg $(1998,2001)$, who called for active personal interventions in power relations and demonstrated how such interventions can be realised; he intentionally participated in the events in Aalborg (2002).

Some individuals possess the power to influence not only particular events, but the triple spiral of evolution, too. Drawing on Bourdieu's concepts of field, capital and habitus, Jones described mutual interactions between a field of architecture (an evolving system) and an elite group of architects (powerful individuals): "One of the distinctive characteristics of the powerful in any field is their capacity to shape the field as well as being shaped by it (Jones 2011: 14). "[Elite] architects operating in the restricted part of the architectural field have greater capacity to define the capitals worth competing for - to define what is valuable and what is not [within the field]" (Ibid.: 15). There is "the different capacity of actors in different positions in the field to construct what became definitive claims about the world" (Ibid.: 28-29).

Even though Jones addressed architects and not planners, his book is relevant here it illustrated how individuals who wanted to succeed (i.e. earn professional influence) needed to adapt to the rules of a particular system (the professional field), and, vice versa, how individuals who obtained sufficient power that was based on the system's rules (i.e. succeeded within the field) were able to influence such systems (the field). The scale of continuous evolution is superior to individuals and yet, individuals are able to change the evolution. But not all of them.

I feel like today we tend to mix up two things: there is an individual as a planner and an individual as a person, and these two individuals are not necessarily the same issue. Their distinction is easily observable when analysing Weber's authority and charisma through the factors of time and scale. Weber (1997) stated that a man's charisma rises through the balance between personal features (the person's characteristics, attitudes and abilities) and historical circumstances (social tensions, demand for new ideas and accidental events). Charismatic power depends on personal ability to use opportunity and lasts only during such opportunity. Charisma is a short-term business. After the historical circumstances end, society's emotions calm down and the power of charisma is supplanted by the power of authority. The legitimacy of authority is rooted in one's position being a part of a bureaucratic system (a planner is in a position which is supported by the legal system). Contrary to charisma, bureaucracy is a long-term mechanism that prefers stability to innovations, slow (or no) modifications to radical changes, and standard processes to 
creativity. From the perspective of time and scale, Weber's distinction is very similar to Machiavelli's description of gaining power and keeping power. Both Weber and Machiavelli warned that the power of the individual (person) is something different from the power of authority (a planner), and these two powers work in different mechanisms. Coming back to Jones (2011), the power of elite architects differs from the power of most architects. The power of most architects is rooted in the rules of a field (system) whereas the power of elites requires a privileged position within a field together with personal talent, abilities and endeavour. To remain in the elite requires a lot more than just the authority of a system.

In line with Jones's claims, most planners refer to their power as the power of authority; thus they highlight correct processes, legal rules and standard methods rather than social activism, interventions or experiments. However, legitimate authority makes planners routine bureaucrats who behave under the system rather than creative leaders who might interfere with the system. Since spontaneous human actions refer to individuals rather than positions, the system, and authority as a part of the system, is not able to deal with them. Individual power beyond position (charisma rather than authority) requires individual features adequate to circumstances; hence, only a few planners can truly follow Flyvbjerg's call. Moreover, the scale of individuals as humans is easily biased by non-rational influences. The following illustrates the interaction between planning and subliminal aspects. It suggests that planners' expectations about how planning works could be, in fact, merely a false assumption.

As I already stated when discussing the element of participants' behaviour, spontaneous human actions are common, influential and unavoidable; however, literature exploring emotions, intuition and sudden actions in planning is still rare. Among the few publications, Baum (2011) discussed irrational thinking, emotions and moral interests in planning. Quoting Mannheim, who "recognized the dangers of unconscious desires and anxieties to social justice and social order" and "contended that planners who chose to assume that people acted rationally would misunderstand society and be impotent to regulate it" (Mannheim 1940, cited in Baum 2011: 114), Baum suggested planners treat people as nonrational beings and involve more psychology in planning. Hoch argued that "useful human judgment combines logic and feeling" (Hoch 2006: 372) and planners should look for inspiration "in disciplines less familiar to planning analysts; psychology, social psychology, neurophysiology, philosophy and literature" (Ibid.: 368). Schröder, Stewart and Thagard (2014) presented a theory of how intentions (which inform actions) are formed by four semantic pointers: how one represents a situation at hand, his/her implicit and explicit attitudes, the anticipated consequences of actions and self. Dobrucká (2017) argued that due to the rational and emotional features of semantic pointers, intentions can be based on deliberate thinking as well as subliminal feelings. Hence, in planning, the time-spatial features of intentions (a deliberate orientation towards a relevant scale and time of planning) might help to inhibit automatised behaviour (sudden here-and-now reactions).

Since planning discourse lacks the deeper investigations of the subliminal fringe, some authors from the fields of psychology, behavioural science and neuroscience are quoted here. Kahneman (2011) argued that humans' decisions are not rational as they are determined by subliminal factors; moreover, these determinants do not need to be relevant, objective or even true. He pointed to the influence of framing (how a problem is formulated shapes how 
the problem is solved), heuristics (the "hurrah" effect), priming (the first idea which comes to mind sets up the direction in which people think), anchoring (people make estimations close to the first offered alternative), the ignorance of time (the intensity of emotions prevails over how long the experience lasts), an aversion to risk in cases of expected profit and, on the contrary, a preference for risk in cases of expected loss (regardless of what is objectively better), and other subliminal factors. In Kahneman's experiments, even a screen saver could modify the result.

Thaler and Sunstein (2009) added that individuals tend to join social groups (whatever the reason may be), conform to common judgement to avoid exclusion (even if they know the group's opinion is wrong), and adapt to traditions (no matter how obscure the beginning of such a tradition was). People easily become inspired by others' assertions; if an assertive participant speaks up at the beginning of a meeting, as usually happens in real life, he/ she dominates the group's decision. According to Damasio (2000), the impact of emotions is enormous, too. For instance, altruism is a decision between current discomfort and a future good feeling ("we helped") compared to current discomfort and a future bad feeling (the moral shame that we did not help). Social pressure appeals to emotions rather than rational awareness. Feelings co-form individuals' intentions as they play a crucial role in how individuals represent the current situation, value possible future outcomes, and understand their own self-image. The arguments presented here suggest that a consensus reached by the participants in a group debate would be merely an illusion. Instead of real agreements, participants are often simply anchored in the first speaker's topic, insist on the status quo because it seems easier, or comply with the most assertive stream.

A prevailing opinion today is that citizens know what they want, and can learn how to make adequate decisions about city development. But Thaler and Sunstein proved that, when it comes to humans' ability to make decisions in complex situations, people make choices that are neither "in their best interest" nor "better than the choices that would be made by someone else" (Thaler and Sunstein 2009: 9), and "the evidence does not suggest that education is, in and of itself, an adequate solution" (Ibid.: 111). They strongly advise nudging participants in the desired direction when tasks which are complex, occasional (not repetitive), lack immediate feedback and/or previous experience, action and result are not obviously connected to each other, and whose impact cannot be foreseen - and planning is definitely such a case. There is always a "pre-setting", the first choice which comes to participants' minds due to subliminal perceptions. Planners' ignorance of such pre-settings, or reluctance to address them actively, simply means allowing someone else to do so; usually someone powerful who does not hesitate to manipulate others.

Based on the above, Forester's (1982) use of information, agenda-setting, and moderation, which are greatly emphasised in planning today, are not enough. Planners should play a more active role in setting factors of which other participants are unaware, anticipate not only misinformation but emotional responses, too, and pay attention to timing, atmosphere and even the decoration of meeting rooms (such as screen savers). Also, planners' role as guardians of procedures is highly insufficient; they need to interfere in the content of such procedures to actively inhibit participants' automatic reactions, propose an adequate "starting point", and ensure adequate substantive considerations. Since experiments in other 
scientific fields have proved that subliminal perceptions influence society far more than we generally admit, planners should rethink this kind of power, include it deliberately in their roles, and use pre-settings to influence results in a substantive manner.

\section{Conclusion}

This article has offered a critical review of the state of art in the subject of how power has been perceived by past and present thinkers, how urban/spatial planners have reflected diverse traditions, particularly at the level of municipalities, and how various approaches by which power is understood, studied and evaluated can be systematised according to the factors of time and scale. The lenses of time and scale revealed that there are some features of power which are yet not fully recognised by planners - for instance the power of subliminal factors - and advised planners to rethink their commonly agreed roles.

The perception of power differs significantly according to whether planners favour continuous evolution or discontinuous eras. In the first case, this article has argued that the development of cities remains a spiral consisting of three elements: context, intentions and participants' behaviour. Planners pondering development as a whole usually identify power in this triple spiral itself, and, consequently, prefer small modifications instead of radical interventions. A desire to understand the complex processes by which cities evolve puts planners in a rather passive role as trend-watchers, analysts and moderators. In the second case, planners' roles modify according to how continual evolution is disconnected, through which element, and how the factors of space and time are applied. As the spiral contains three elements, there are three options for disconnecting it. If the element of context is understood as the fundamental base, planners see their role mainly as describing the situation at hand and opposing those with power by providing relevant information, setting up appropriate agendas and keeping to specific terms. Planners who highlight the element of intentions and follow values that are believed to be universal (such as ethics, justice, democracy, tolerance and similar) often see their role as keeping an eye on fair processes, maintaining a balance among participants, striving for mutual trust, and being advocates of those without power. The third alternative for disconnecting the triple spiral of evolution, the element of participants' behaviour, is not sufficiently addressed in current planning discourse, which largely neglects emotional, intuitive and sudden human actions.

In all three cases, the volatility of the factors of scale and time allows for a significant variety of alternatives which reflect specific situations while remaining structured. They help us to see each approach to power as complementary to other approaches and to understand various planners' roles within a more holistic picture. As an example, this article compared the approaches of Habermas and Foucault, Flyvbjerg and Healey, and authors promoting practical and normative ethics. The factor of time was particularly observed through Machiavelli's view of gaining power versus keeping power, and Weber's power of charisma contra power of authority. Both warn that power as it works during short-term acts differs fundamentally from power as a long-term endeavour. Even though the roles of time and scale are generally accepted in planning, these two factors are often underestimated. This claim was supported by considering complexity theories in planning. Authors promoting 
complexity tend to ponder "everything" during projects that are relatively short-term, spacelimited and unstable, but their ambition often leads to a passive attitude.

The last part of this article paid attention to the power of individuals, especially the power of individuals' subliminal perceptions. Studies exploring the role of individuals, their personalities and subliminal perceptions in planning are rare in the planning discourse; however, experiments in other scientific fields prove that their influence is crucial. Subliminal factors, such as who speaks up first, the emotional feeling of a meeting, which opinions are assumed to be acceptable by social groups, how participants understand their self-image, and what association is the strongest, possess power to shape outcomes. Hence, the person who leads participants' discussion makes a difference. The leader is allowed to frame, prime and anchor the debate as well as keep track of how participants deal with the long-term perspective, the intensity of emotions, and risk. In this perspective, the currently accepted roles of planners should be enlarged to nudge participants in the desired direction; to frame a problem adequately; to collect relevant information leading to decision-making; to anchor the discussion; to control individual speakers, social pressure and the emotional atmosphere; to reflect and evaluate; and to inhibit automatic reactions in favour of substantive considerations.

\section{References}

ARENDT, Hannah. 1958. The Human Condition. Chicago: University of Chicago Press.

ARENDT, Hannah. 1979. The Origins of Totalitarianism, New edition with added prefaces. San Diego: A Harvest and HBJ Book.

BATTY, Michael. 2010. "Complexity in City Systems: Understanding, Evolution, and Design." Pp. 99-121 In A Planner's Encounter with Complexity, edited by Gert DE ROO and Elisabete A. SILVA. Burlington, VT: Ashgate.

BAUM, Howell. 2011. "Planning and the Problem of Evil." Planning Theory 10(2): 103-123.

BOURDIEU, Pierre. 1977. Outline of a Theory of Practice. Cambridge: Cambridge University Press.

CAMPBELL, Heather and Robert MARSHALL. 1998. "Acting on Principle: Dilemmas in Planning Practice." Planning Practice and Research 13(2): 117-128.

CAMPBELL, Heather and Robert MARSHALL. 1999. "Ethical Frameworks and Planning Theory." International Journal of Urban and Regional Research 23(3): 464-478.

CHRISTENSEN, Karen S. 1985. "Coping with uncertainty in planning." Journal of the American Planning Association 51(1): 63-73.

DAMASIO, António R. 2000. Descartes'Error: Emotion, Reason, and the Human Brain. New York: Quill.

DE ROO, Gert. and Elisabete A. SILVA, eds. 2010. A Planner's Encounter with Complexity. Burlington, VT: Ashgate.

DE ROO, Gert. 2010. "Being or Becoming? That is the Question! Confronting Complexity with Contemporary Planning Theory.” In A Planner's Encounter with Complexity, edited by Gert de ROO and Elisabete A. SILVA. Burlington, VT: Ashgate.

DOBRUCKÁ, Lucia. 2017. "When Planners Depend on Powerful Actors: Automatism Versus Intentions." Planning Theory 1-19. Published OnlineFirst on March 24 $4^{\text {th }}$ 2017. http://journals.sagepub.com/doi/ pdf/10.1177/1473095217698725.

FLYVBJERG, Bent. 1998. Rationality and Power: Democracy in Practice. Chicago: University of Chicago Press. 
FLYVBJERG, Bent. 2001. Making Social Science Matter: Why Social Inquiry Fails and How It Can Succeed Again. Cambridge: Cambridge University Press.

FLYVBJERG, Bent. 2002. "Bringing Planning to Planning Research: One Researcher's Praxis Story." Journal of Planning Education and Research 21: 353-366.

FORESTER, John. 1982. "Planning in the Face of Power." Journal of the American Planning Association 48(1): 67-80.

FORESTER, John. 1989. Planning in the Face of Power. Berkeley: University of California Press.

FORESTER, John. 1999. "Reflections on the Future of Planning Practice." International Planning Studies 4: 175-193.

FORESTER, John. 2000. The Deliberative Practitioner: Encouraging Participatory Planning Processes. Cambridge, MA: MIT Press.

FOUCAULT, Michel. 1979. Discipline and Punish: The Birth of the Prison. New York: Vintage Books.

FOUCAULT, Michel. 1998. The History of Sexuality: The Will to Knowledge, Vol. 1. London: Penguin Books.

FOUCAULT, Michel. 2007. Security, Territory, Population: Lectures at the Collège de France 1977-78, edited by Michel SENELLART. Basingstoke: Palgrave Macmillan.

FOX-ROGERS, Linda and Enda MURPHY. 2014. "Informal Strategies of Power in the Local Planning System.” Planning Theory 13(3): 244-268.

GETIMIS, Panagiotis. 2012. "Comparing Spatial Planning Systems and Planning Cultures in Europe: The Need for a Multi-scalar Approach." Planning Practice and Research 27(1): 25-40.

GRANGE, Kristina. 2014. "In Search of Radical Democracy: The Ideological Character of Current Planning Advocacies for Culture Change in Planning." Environment and Planning A 46: 2670-2685.

GUNDER, Michael. 2003. "Passionate Planning for the Others Desire: An Agnostic Response to the Dark Side of Planning." Progress in Planning 60: 235-319.

GUNDER, Michael. 2010. "Planning as the Ideology of (Neo-liberal) Space." Planning Theory 9(4): 298-314.

GUNDER, Michael. 2011. “Fake It Until You Make It, and Then...” Planning Theory 10(3): 201-212.

GUNDER, Michael and Jean HILLIER. 2009. Planning in Ten Words or Less: A Lacanian Entanglement with Spatial Planning. Farnham: Asghate.

HABERMAS, Jürgen. 1984. The Theory of Communicative Action: Reason and the Rationalization of Society, Vol. 1. Boston: Beacon Press.

HABERMAS, Jürgen. 1990. Moral Consciousness and Communicative Action. Cambridge, MA: MIT Press.

HABERMAS, Jürgen. 1992. The Structural Transformation of the Public Sphere: An Inquiry into a Category Bourgeois Society. Cambridge, MA: MIT Press.

HEALEY, Patsy. 1992. “A Planner's Day: Knowledge and Action in Communicative Practice.” Journal of the American Planning Association 58: 9-20.

HEALEY, Patsy. 1997. Collaborative Planning: Shaping Places in Fragmented Societies. Basingstoke: Macmillan.

HILLIER, Jean, Gert de ROO and Joris Van WEZEMAEL. 2012. Complexity and Planning Systems, Assemblages and Simulations. Burlington, VT: Ashgate.

HOCH, Charles. 2006. "Emotions and Planning.” Planning Theory \& Practice 7(4): 367-382.

HOEKVELD, Gerard and Barrie NEEDHAM. 2013. "Planning Practice between Ethics and the Power Game: Making and Applying an Ethical Code for Planning Agencies." International Journal of Urban and Regional Research 37(5): 1638-1653.

HOUDÉ, Olivier and Grégoire BORST. 2014. "Measuring Inhibitory Control in Children and Adults: Brain Imaging and Mental Chronometry." Frontiers in Psychology 5(616): 1-7. 
JONES, Paul. 2011. The Sociology of Architecture: Constructing Identities. Liverpool: Liverpool University Press.

KAHNEMAN, Daniel. 2011. Thinking Fast and Slow. London: Allen Lane.

LUKES, Steven. 2005. Power: A Radical View. Basingstoke: Palgrave Macmillan.

MACHIAVELLI, Niccolò. 1998. The Prince. Translated and with an introduction by Harvey C. Mansfield. Chicago: University of Chicago Press.

MACINTYRE, Alasdair. 1988. Whose Justice? Which Rationality? London: Duckworth and Co.

MANNHEIM, Karl. 1940. Man and Society in an Age of Reconstruction. New York: Harcourt, Brace and World.

PLØGER, John. 2004. "Ethics in Norwegian Planning: Legitimacy, Ambivalence, Rhetoric.” Planning Practice and Research 19(1): 49-66.

PURCELL, Mark. 2009. "Resisting Neoliberalization: Communicative Planning or Counter-Hegemonic Movements." Planning Theory 8(2): 140-165.

RICHARDSON, Tim. 2005. "Environmental Assessment and Planning Theory: Four Short Stories about Power, Multiple Rationality, and Ethics." Environmental Impact Assessment Review 25: 341-365.

SAGER, Tore. 2015. "Ideological Traces in Plans for Compact Cities: Is Neo-liberalism Hegemonic?" Planning Theory 14(3): 268-295.

SANDERCOCK, Leonie. 2005 "Picking the Paradoxes: A Historical Anatomy of Australian Planning Cultures." Pp. 309-330 in Comparative Planning Cultures, edited by Bishwapriya SANYAL. New York: Routledge.

SCHMIDT-THOMÉ, Kaisa and Raine MÄNTYSALO. 2014. "Interplay of Power and Learning in Planning Processes: A Dynamic View.” Planning Theory 13(2): 115-135.

SCHRÖDER, Tobias, Terrence C. STEWART and Paul THAGARD. 2014. "Intention, Emotion, and Action: A Neutral Theory Based on Semantic Pointers." Cognitive Science 38: 851-880.

STEIN, Stanley M. and Thmas L. HARPER. 2003. "Power, Trust, and Planning." Journal of Planning Education and Research 23: 125-139.

THALER, Richard H. and Cass R. SUNSTEIN. 2009. Nudge: Improving Decisions about Health, Wealth and Happiness. London: Penguin Books.

VAN ASSCHE, Kristof, Martijn DUINEVELD, Raoul BEUNEN and Petruta TEAMPAU. 2011. "Delineating Locals: Transformations of Knowledge/Power and the Governance of the Danube Delta." Journal of Environmental Policy and Planning 13(1): 1-21.

VAN ASSCHE, Kristof, Raoul BEUNEN and Martijn DUINEVELD. 2012. "Performing Success and Failure in Governance: Dutch Planning Experiences.” Public Administration 90(3): 567-581.

WATSON, Vanessa. 2006. "Deep Difference: Diversity, Planning and Ethics." Planning Theory 5(1): 31-50.

WEBER, Max. 1997. Autorita, etika a společnost: Pohled sociologa do dějin [Authority, Ethics and Society: Sociologist's View on the History]. Prague: Mladá Fronta.

\section{Author}

Lucia Dobrucká works at the Czech Technical University in Prague, Masaryk Institute of Advanced Studies, and explores the concept of power; how power changes according to the factors of scale and time, its connection to individuals' perceptions, intentions and decisions, and what factors help planners to challenge powerful actors on which they financially depend. Contact:1dobrucka@gmail.com 